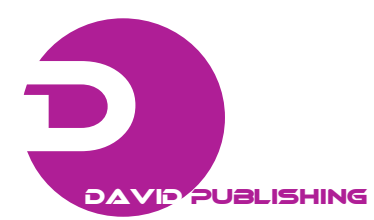

\title{
High Alkaline Ionized Water Will Save Future
}

\section{Generations}

\author{
Tamio Matsuzawa \\ E-Plan Co., Ltd., Japan, (EPCO), 1-17-15 Kitahonnmachi, Funahashi-shi, Ciba, Japan \\ Corresponding author's e-mail:t-matsuzawa@e-wash.jp
}

\begin{abstract}
Scientifically, high alkaline ionized water (HAIW) with $\mathrm{pH}$ more than 11.5 is proven to have unique capability as strong cleaner, sanitizer and deodorizer competitive enough to relative chemical products even if it is nearly 99.9\% pure water. E-Plan Co., Ltd., Japan, (EPCO) manufactures state of the art machine to produce HAIW (with pH 12.5 above) patented proprietary electrolyte ionizing technology in pursuit of challenging goal to change concept of safety of food products and to make our eating habit more secured. History of HAIW is obscure and inarticulate. HAIW as water products are sold with naive and misleading catchwords. Almost no HAIW suppliers promote machines to produce HAIW. EPCO, while promoting HAIW products with brand name of e-wash, is striving to develop and supply proprietary, smallest, trouble free, easy to operate and least expensive HAIW producing machine to homes and businesses to be widely used. EPCO's objective is to encourage consumers at homes and users at all kinds of industries and businesses to replace as much chemical products they use as possible with HAIW. Not all vegetable products can be chemical free and not to make 6.0 billion people on this planet starved. Then wash vegetables with a lot of chemical detergent with full of artificial surfactant hazardous to human, and destroying rivers, lakes and environment by discharging chemicals, consequently make ourselves and future generation sick by consuming attached chemical compounds in the vegetables which we are forced to eat if not safely removed. EPCO believes solution is HAIW, as it contains full of hydroxide ion with 600 oxidization reduction potential (ORP), working as natural surfactant, sanitizer and deoxidizer, will provide better solution for the safety of food products both at homes and businesses.
\end{abstract}

Key words: High alkaline ionized water, strong cleaner, sanitizer, deodorizer, EPCO. 